\title{
Chile mira hacia China. Relaciones en una nueva era
}

\author{
Augusto Soto Alvarez
}

Augusto Soto Alvarez. Sinólogo. licenciado en Historia, Universidad Católica de Valparaíso, esTUdIOS DE POSTGRADO EN HISTORIA CONTEMPORÁNEA EN LA UNIVERSIDAD DE BEIJING Y DOCTORANDO EN LA UNIVERSIDAd AUTÓNOMA DE Barcelona. Ha SIDO REPORTERO DE LA AGENCIA DE NOTICIAS EFE EN BEIJING Y ACTUALMENTE TRABAJA COMO CONSULTOR EN ASUNTOS CHINOS EN BARCELONA Y EN PROYECTOS DE LA UNIÓN EUROPEA EN ASIA CENTRAL. 
La «Gran China» es clave para Chile. Profundizar las relaciones entre ambos requerirá de personal con habilidades adicionales, que enriquezcan el currículo de la diplomacia y el empresariado, especialmente si Santiago también desea jugar la relevante función de puente entre Asia y América del Sur. En este arti- 
culo se revisan las percepciones chilenas de China y los notables aciertos en las relaciones bilaterales, se esbozan una serie de medidas que Chile puede adoptar por sí sólo, así como acciones conjuntas que pueden emprenderse con otros países de la región con el fin de optimizar sus relaciones con el gigante asiático. 


\section{Introducción}

La estrategia de promoción y fortalecimiento de la presencia en el Asia-Pacífico, es coherente con los intereses de Chile y las tendencias de globalización. La «Gran China», una realidad nacional y transnacional que incluye a Beijing y Taipei, es un mercado que ocupa el tercer lugar como principal destino de las exportaciones del país y el sexto como principal origen de sus importaciones. $Y$ esta tendencia es probable que se incremente en el largo plazo. ${ }^{1}$

Durante la década de los ochenta, altos funcionarios gubernamentales, hombres de negocios y periodistas chilenos subrayaron la idea de situar a China y Japón en el horizonte de los destinos estratégicos y económicos del país. Durante esta década, por primera vez en la historia nacional, dos presidentes sucesivos han mantenido conversaciones con jefes de Estado chinos en discusiones bilaterales y multilaterales. Más aún, los presidentes han visitado Asia acompañados de grandes delegaciones de empresarios. Seriedad y cohesión es la imagen que el país ha querido transmitir en el Extremo Oriente, unida a la difusión del excelente balance macroeconómico durante la última década. Más aún, altos funcionarios chilenos también han manifestado que el país ha de jugar un papel de puente entre América del Sur y la región del Asia Pacífico.

Este artículo perfila la actitud chilena en el pasado reciente y en la actualidad, y afirma que la política oficial, tan buena como ha sido hasta ahora, debiese evolucionar hacia un enfoque más refinado, si no se desea arriesgar la posibilidad de estancamiento o atraso frente a competidores con un conocimiento más sofisticados. Este nuevo nivel requerirá de personal con habilidades adicionales, que enriquezca el círculo de la diplomacia y el empresariado, especialmente si Santiago también desea jugar la relevante función a que aspira entre Asia y América del Sur. No obstante, el proceso de reajuste comienza en la escuela básica.

Se argumenta que el sistema educacional, la tradición diplomática, las formas occidentales de hacer negocios y la reciente historia política de Chile contiene, junto con aciertos notables, barreras y oportunidades. Aquí se esbozan unas ideas en las que hay que profundizar y concretar para mejorar los vínculos con el país que, probablemente, se convierta en el mayor mercado mundial, así como en una superpotencia política y científica dentro de pocas décadas.

\footnotetext{
${ }^{1}$ Este artículo fue escrito en mayo de 1998. No hay necesidad de insistir que en los próximos meses las cifras se verán probablemente modificadas por la crisis asiática.
} 


\section{China en Chile}

¿Está Chile preparado para asimilar totalmente la noción y la importancia de China? La respuesta parece estrechamente ligada a una ambigua y vaga idea del Pacífico como suerte de «destino manifiesto». El Océano Pacífico se ha considerado vital para los destinos de la nación desde los años posteriores a la Independencia. La incorporación de la Isla de Pascua al territorio nacional, en 1888, fortaleció la tendencia chilena a considerarse como un país perteneciente a la Cuenca del Pacífico. Desde 1845 hasta fines de siglo, consulados chilenos fueron abiertos en Cantón, Hong Kong y una oficina comercial en China, aparte de otros consulados a través de Asia y Oceanía. Después de la victoria en la Guerra del Pacífico (18791883), cerca de 1100 chinos se incorporaron al Estado chileno. Al poco tiempo, en 1915, Santiago y Beijing establecieron relaciones diplomáticas. ${ }^{2}$

A través de gran parte del siglo XX los intereses de Chile se han definido en relación con los Estados Unidos, América Latina y Europa. China y el Asia-Pacífico han permanecido alejadísimos de la conciencia nacional. Prejuicios y percepciones deficientes han constituido un vacío difícil de llenar. La distancia se ha asentado en diferencias étnicas y culturales -el miedo al «peligro amarillo» prevalecía en Occidente-, ampliadas por los dramáticos acontecimientos políticos que tenían lugar tras el colapso de la dinastía Qing. El sentido de distancia inabarcable fue aumentado por la enorme barrera geográfica representada por el Océano Pacífico. ${ }^{3}$

Los alineamientos estratégicos y militares de la Guerra Fría obstruyeron las relaciones entre ambos lados del Océano Pacífico. Chile no fue una excepción. Durante décadas Santiago reconoció a Taipei como el único representante de China.

Pero al cerrarse la década de los sesenta, el nuevo gobierno se sintió confiado para realizar una maniobra excepcional en el contexto latinoamericano. Con el presidente socialista Salvador Allende en el poder, Chile fue el primer país sudamericano en establecer relaciones diplomáticas con Beijing, en diciembre de 1970. Pese al ambiente de confrontación ideológica vivida en Chile hace casi tres décadas, se dio un consenso en la izquierda y la derecha del espectro político en torno a la idea de que la República Popular China representaba una realidad que trascendía la pugna ideológica. Como lo expuso el influyente periódico conservador El Mercurio:

"Es indudable que la exclusión de China Continental imposibilitaba a Chile para formu-

${ }^{2}$ Véase a Hernán Gutiêrrez y Lin Chou, «Relations between the Republic of China and the Republic of Chile, Occasional Papers/Reprint Series in Contemporary Asian Studies, $n^{\circ}{ }_{1}$, (1995): $16-17$.

${ }^{3}$ Para este tema es de utilidad el trabajo pionero de Pilar Armanet et al., Latín American Perceptions on the Pacific Basin. Evolution and Prospects (Santiago: Instituto de Estudios Internacionales de la Universidad de Chile, Serie de Publicaciones Especiales $\left.n^{\circ} 65,1985\right): 12$. 
lar una política exterior genuinamente global y cerraba el acceso a un mercado de vastas proporciones que ahora podría abritse a los productos nacionales". 4

Pese al golpe militar de 1973 y a los alineamientos de la Guerra Fría, no se esfumó la idea de que la nación asiática era importante. En la década de los ochenta, el régimen llegó a la conclusión de que debía fortalecer sus lazos con los países que evitaban condenar a Chile por abusos en derechos humanos. ${ }^{5}$ Beijing, como miembro del Consejo de Seguridad de Naciones Unidas, así como otros países asiáticos, eran un activo que podría ayudar a desarrinconar al régimen políticamente aislado en la arena internacional. No fue un accidente que en esa época Chile proveyera logística a un asentamiento chino en la Antártida.

A la vez, la Armada, llegó a la conclusión de que el destino de Chile yacía en el Océano y más allá de sus horizontes. Esta idea se potenció por el hecho evidente de que 4.500 kilómetros de Chile enfrentan al Pacífico. El mar como fuente de inmensos recursos naturales y como vía hacia Asia y al gigantesco mercado representado por la apertura de China al exterior fueron a menudo mencionados por los medios de comunicación, así como por los círculos académicos a lo largo de la década de los ochenta. ${ }^{6}$ Pero el fallido viaje de Pinochet a Filipinas señaló un estancamiento del compromiso en la región del Asia-Pacífico. Sin embargo, el comercio con Asia se incremento espectacularmente, especialmente con Japón, Corea y la Gran China. En el caso de la República Popular China el primer joint-venture entre Beijing y un país latinoamericano fue firmado con una compañía chilena de cobre, en $1987 .^{7}$

La propaganda lanzada por el régimen militar contra el comunismo internacional siempre definió a Moscú como el líder de una conspiración mundial antichilena a la que no se sumaba Beijing. Una figura pública como Luis Ayala, hoy ex presidente de la Confederación de la Producción y el Comercio, indicó más de una vez a los medios de comunicación que la República Popular China a diferencia de la URSS, no era una potencia expansionista. ${ }^{8}$

En 1989, Tienanmen y la caída del Muro de Berlín ayudaron a deslucir el papel de Beijing. Durante un corto período de tiempo se reavivó en Chile el interés en la extinta Unión Soviética. Pero los dramáticos sucesos políticos vividos por Moscú y el subsecuente declive de los niveles de vida de las ex repúblicas soviéticas mostraron que ese espacio económico no iba a representar un Oriente económico significativo para Chile.

\footnotetext{
${ }^{4}$ El Mercurio, 14 de enero de 197:, citado por Javier Matta, Las relaciones bilaterales entre Chile y la República Popular China, tésis de Magister en Relaciones Internacionales (Santiago: Instituto de Relaciones Internacionales de la Universidad de Chile, 1993): 83 .

${ }^{5}$ Manfred Wilhelmy y Rosa María Lazo, «La política multilateral de Chile en Asia-Pacífico, en Estudios Internacionales, $n^{\circ} 117$ (enero-marzo, 1997): 7 .

6 Véase Augusto Varas (ed.), Hacia el siglo XXI. La proyección estratégica de Chile (Santiago: FLACSO, 1989).

7 Tal fue el Beijing Santiago Tube Copper Company, cuyo objetivo era producir tubos de cobre en Beijing para el mercado chino y el resto de Asia. El proyecto fue disuelto a comienzos de esta década.

${ }^{8}$ Entrevista reciente sobre la importancia del pais asiático para Chile, en «Negociador en China», El Mercurio, 29 de junio de 1997.
} 


\section{Un nuevo período en las relaciones bilaterales}

En noviembre de 1993 la televisión nacional transmitió una poderosa aunque breve imagen filmada en la costa. Significativo fue ver al candidato presidencial explicando su programa en un anuncio televisivo de cara al Pacífico. Eduardo Frei describió su proyecto de gobierno dando por sentada la importancia económica del Océano Pacífico y de los países de la Cuenca. Este fue un hecho decidor en un país que, pese a la retórica de los últimos años, se ha seguido orientando hacia el interior, cuya dieta, a diferencia de lo que ocurre en Japón, atribuye una importancia subordinada a los productos del mar, y cuya capital, interior, concentra a casi la mitad de la población. Pocos meses después de la campaña electoral, el presidente Frei declaró:

"Uno de los objetivos principales de nuestra política exterior es integrarse al espacio del Asia-Pacífico, actualmente uno de los focos más dinámicos de la economía mundial. Esta es una nueva frontera para la cual el mar es el camino natural de comunicación e intercambio. Nuestra situación geográfica privilegiada nos convierte también en un natural puente hacia el Asia-Pacífico para otros países latinoamericanos"."

La admisión de Chile como miembro de APEC, en 1993 -con el apoyo de Beijing, entre otros países-, representó un hito en la política exterior chilena. Así, Santiago oficialmente sancionó la tendencia que hacia finales de 1997 la hacía comerciar más con Asia que con América Latina, América del Norte o Europa.

En noviembre de 1995, Frei visitó China y uno de los resultados de la visita fue un renovado impulso de las relaciones bilaterales. Éste se expresó claramente en la decisión de establecer un consulado en Shanghai, en $1996 .^{10}$

A mitad de esta década se ha verificado que casi un $75 \%$ de las exportaciones chilenas se han desglosado en cobre, celulosa y harina de pescado. De esta cifra, un $25 \%$ era cobre. Fuentes de 1997 indican que el mercado chino, que incluye a Beijing y Taipei, fue el tercer destino para las exportaciones chilenas, después de Estados Unidos y Japón, y la sexta fuente de importaciones, después de México y sobrepasando a Alemania y Japón. ${ }^{11}$ Además, Chile ha diversificado la exportación de productos agrícolas, forestales y del mar.

Puesto que la demanda hacia el sector del cobre ascenderá a por lo menos un millón de toneladas métricas al año, y la probable superpotencia necesitará -en un futuro a medio plazograndes cantidades, las negociaciones también se han centrado en la posibilidad de atraer

\footnotetext{
9 "Discurso presidencial en ocasión del mes del mar», Revista chilena de geopolítica, Santiago, n 3 (agosto, 1994): 4

${ }^{20}$ En ese año y en contraste, un país como España, con antiguos y crecientes lazos comerciales en China, aún no tenía un consulado en Shanghai.

"Banco Central de Chile, Indicadores de Comercio Exterior (Santiago: enero-agosto, 1997): 1936, 1998. Tambiên véase Economist Intelligence Unit. Chile Country Report (Londres, Economist Intelligence Unit, 4th quarter 1997$): 5$.
} 
inversiones chinas en la industria cuprífera chilena para iniciar proyectos conjuntos en el sector. Durante los dos últimos años se han estado discutiendo planes para una venta chilena de know-how cuprífero a Beijing. Igualmente, la Corporación Nacional China de Metales no Ferrosos ha contactado a las compañías chilenas correspondientes como parte de un plan para invertir en explotación cuprífera en Chile. ${ }^{12}$

Otro campo de colaboración ha sido el uso pacífico de la energía atómica y la exploración de formas de cooperación en la industria espacial.

Durante la visita presidencial, en 1995, se firmó un acuerdo que contempla la concesión mutua de derechos marítimos y portuarios. También se firmó un acuerdo forestal, que incluye procesamiento y comercialización de la producción. ${ }^{13}$ Chile se ha interesado particularmente en la materialización del anuncio chino hecho en la cumbre de APEC, en 1995, sobre significativas reducciones de tarifas, que incluyen a frutas y verduras y que beneficiaría concretamente al salmón, el vino y la uva. Actualmente, sólo manzanas y peras son exportadas a la República Popular China y hace sólo pocos meses la uva comenzó su entrada en el mercado chino. ${ }^{14}$

Recientemente una compañía vitivinícola chilena se ha establecido permanentemente en Beijing para maximizar sus ventas. Una gran revolución está ocurriendo en los hábitos alimenticios y el vino es uno de los nuevos productos en la demanda. La dinámica industria vitivinícola chilena orientada hacia el exterior ve grandes oportunidades y también la industria salmonera. Hay conversaciones para explotar conjuntamente especies de salmón que no existen en América del Sur. ${ }^{15}$ A la vez, se espera que en el país más poblado eche raíz la gestión privada de los fondos de pensiones, uno de los rubros en el que los chilenos tienen más experiencia. Como corolario, para el año 2000, el objetivo de ProChile -la oficina oficial que fomenta las exportaciones del país- es llegar a los 2 mil millones en el intercambio comercial con China. ${ }^{16}$ Más aún, la oficina en el país oriental concentra el mayor presupuesto de ProChile en Asia y Oceanía. ${ }^{17}$

\footnotetext{
12 Li Peng, "A new chapter in Chinese/Latin American-Caribbean Cooperation", en Capítulos del SELA. Special Number (1996): La baja de la demanda cuprifera en Asia derivada de la crisis señala un compás de espera a estas proyecciones previas.

${ }^{23}$ La Nación (Santiago de Chile), 25 de novlembre de 1995; El Mercurio (Santiago de Chile), 26 de noviembre de1995.

${ }^{14}$ Véase "China: favorables perspectivas para exportaciones frutícolas", El Mercurio, 15 de abril de 1998.

${ }^{15}$ En 1996 Chile fue el segundo productor de salmón después de Noruega.

${ }^{16}$ Importaciones y exportaciones chilenas a la República Popular China en los últimos seis años (En millones de dólares, incluyendo a Hong Kong).
}

$\begin{array}{lllllll} & 1992 & 1993 & 1994 & 1995 & 1996 & 1997^{\star} \\ \text { EXPORTACIONES } & 368,4 & 256,4 & 217,5 & 375,2 & 466,7 & 548,5 \\ \text { IMPORTACIONES } & 22,2 & 300,6 & 363,1 & 498,5 & 635,8 & 654,8\end{array}$

*Cifras de noviembre de 1997. Fuente: Banco Central de Chile.

${ }^{17}$ Entrevista con Guillermo Garrido, gerente de ProChile para Asia y Oceanía, 13 de enero de 1998. 
Los índices de crecimiento económico, la estabilidad política y el estatus de único país sudamericano miembro de APEC hasta hace muy poco, han llevado a varias autoridades a subrayar que las compañías deben aprovechar la ventaja de esta situación y adelantar más en el estado de sus negocios en Asia. Esa percepción indica que esperar equivale a un error. Una vez que los otros países de la región logren positivas y sostenidas cifras macroeconómicas -se argumenta- fortalecerán sus lazos con Asia. ${ }^{18}$

En lista de espera. Por otra parte, países que no son Estados ribereños del Pacífico, como Brasil y Argentina, también comercian con el mercado chino de forma significativa. De hecho, Brasil es el primer socio latinoamericano de China.

Actualmente Chile se acerca a las puertas de entrar en una segunda fase del proceso manufacturero orientado a la exportación. Se sabe que una excelente vía para un país de 14 millones de habitantes es aumentar y diversificar en su estrategia exportadora. Asia constituye una región crucial puesto que provee tecnología y un inmenso mercado hacia donde enviar productos de valor agregado. En este sentido, la industria japonesa y el mercado chino son relevantes. La gradual liberalización de tarifas anunciadas por Beijing ha sido vista hasta hace poco como otro factor crucial para fortalecer la tendencia. De hecho, se espera la firma de un creciente número de empresas conjuntas con participación chilena en la región en los próximos cinco años, según Edgardo Boeninger, ex presidente del Comité Permanente del PECC. ${ }^{19}$

Estas perspectivas han llevado a algunas autoridades a acariciar planes demasiado ambiciosos. Dos ideas se superponen aquí. Junto con el deseo de avanzar posiciones en Asia antes de que se adelanten otros países sudamericanos se subraya la idea de que Chile ha de ser el puente natural entre Asia y el MERCOSUR. ${ }^{20}$ Esto es, entre una región de más de mil quinientos millones de consumidores y otra de 200 millones. El razonamiento dice que a medida que se incrementan los volúmenes de importaciones y exportaciones entre los países atlánticos con los países asiáticos, Chile podría ofrecer mejores accesos al Pacífico por medio de una serie de mejoramientos en ferrocarriles, carreteras y puertos. La materialización de esta idea es probable que lleve muchos años, especialmente debido a la barrera natural formidable que representan Los Andes.

Por añadidura, se ha expresado a altos niveles en Santiago, que Chile podría ser un «interlocutor válido» en Asia no solo para MERCOSUR, sino también para América Latina. Esta es una tarea más compleja para la que no está preparado Chile ni ningún otro país de la región. El

\footnotetext{
18 "Negocios de pequeñas y medianas empresas en el Asia-Pacífico. Tierra de oportunidades y complejidades", El Mercurio, 22 de junio de 1997.

${ }^{19}$ Véase la entrevista concedida por Edgardo Boeninger a La Tercera (Santiago de Chile), 22 de agosto de 1996.

${ }^{20}$ Conviene recordar que desde 1996 la más extensa pista de aterrizaje del país está en Isla de Pascua, a 3.700 kilömetros del continente y se espera que sea un factor de importancia en las relaciones con Asia. Aquí hay que añadir que Perú también desea jugar un papel de puente entre APEC y los países andinos.
} 
Grupo de Río mantiene diálogos regulares de carácter institucional con Beijing. Su agenda incluye al comercio como tema principal, aunque también pretende abordar inversiones mutuas, transportes y comunicaciones, mecanismos de apoyo financiero y el desarrollo de relaciones científicas y tecnológicas. ${ }^{21}$ Un enfoque más realista para el país sería promover sus intereses de forma bilateral y esperar a que el Grupo de Río lo represente en calidad de dialogante regional en sus conversaciones con Beijing.

Indudablemente, las relaciones comerciales de Chile en Asia han precedido su inclusión en APEC. Sin embargo, el acceso a este foro es visto como la promoción oficial a un nuevo estatus que ayudará en las transacciones en unas sociedades asiáticas jerarquizadas, y, particularmente en el complejo mercado chino.

\section{Los factores interculturales}

Es interesante notar que en Santiago se le dedica una gran atención a los foros del AsiaPacífico, -léase APEC, PBEC y PECC, en tanto marcos oficiales para mejorar las relaciones en Oriente- y menos a la implementación efectiva de los planes empresariales en Asia y particularmente en China. Hay una tarea pendiente en un capítulo importante: el conocimiento de la mentalidad de negocios china y la selección de información refinada de cada una de las provincias del país-continente. Inevitablemente, la embajada en Beijing, el consulado en Shanghai y las Oficinas de Promoción de Exportaciones (ProChile) en Hong Kong, Cantón, Beijing y Taipei, no se las pueden haber con todos los desafíos y oportunidades planteados por las complejidades de una mentalidad diferente en un continente que incluye a un $21 \%$ de la población mundial. Trasladado al terreno de los hechos, esto significa que hay un déficit de especialistas en China (Zhongguo long), tanto en los negocios como en la diplomacia. Esto significa personal con fluidez en el idioma chino, conocedor de la mentalidad del país y provisto de conexiones sociales a diferentes niveles. ${ }^{22}$

A esto se añaden ciertos patrones establecidos en el comercio. En otras palabras, la exportación tradicional de minerales y productos primarios es sencilla. Las compañías embarcan la producción y esperan el pago. No obstante, parece que en tanto la economía chilena continúa su crecimiento y diversificación, será conveniente pasar pronto a la venta de productos manufacturados y servicios e invertir en nuevos mercados, y en China hay varios mercados. Las

\footnotetext{
${ }^{21}$ SELA, Elements for Institutional Dialogues Between the Río Group and the People's Republic of China (Nueva York, octubre de 1996).

${ }^{22}$ Sobre este tema, véase Carolyn Blackman, Negotiating China. Case Studies and Strategies (Australia: Allen \& Unwin, 1997); Augusto Soto, “Antecedentes para el entendimiento y la negociaciôn en la República Popular China", en Revista de Estudios Asiáticos, $n^{\circ} 3$ (1996): 201.222.
} 
principales multinacionales así como las empresas medianas de diversos países asiáticos y occidentales disponen de personas que hablan chino y se han familiarizado con las circunstancias del país, resumidas en el concepto de guoqing. Los empresarios chilenos parecen aún no captar bien todas las complejidades de las provincias chinas, las barreras comunicacionales, las peculiaridades del marketing, las redes sociales (guanxi). ${ }^{23}$

En 1990, en una de mis visitas a la embajada chilena en Beijing, un diplomático, reflexionando en voz alta sobre su quehacer se hacía la pregunta inevitable: «qqué piensan los chinos?». Desde entonces, se ha hecho poco para responder la cuestión. La tarea específicamente cultural no se ha abordado aún. Con pocas excepciones, los diplomáticos chilenos no desean aprender chino o permanecer más de tres años en el país asiático. ${ }^{24}$ Vale la pena recordar que entre la comunidad hispanohablante en Beijing es común hablar del Pekinazo, el schock cultural que significa vivir en la capital de una cultura tan alejada.

Hasta donde se sabe, ninguno de los directores de la Santiago Beijing Copper Tube Company -la primera empresa conjunta emprendida por China con un país latinoamericano- entabló una relación fluida con los chinos, aprendiendo la lengua, por ejemplo, hecho que también era apreciado como desventaja por los mismos chilenos. ${ }^{25}$

Necesitamos un involucramiento aún mayor. Las autopistas de la información pueden hacer poco para llenar este vacío. Los estudios muestran que «el diálogo permanente con el socio local es una condición necesaria para el éxito de las sociedades. Específicamente, en vez de informes escritos, es necesario institucionalizar las relaciones cara a cara». ${ }^{26}$ Incluso los encuentros sociales están impregnados de sutiles habilidades de etiqueta que pueden tener aplicaciones en el logro de acuerdos, como han comprendido funcionarios y empresarios chilenos en sus encuentros con sus contrapartes asiáticas en los foros del APEC. ${ }^{27}$

Desde 1990 no hay más generales ni almirantes en Beijing representando a Santiago a nivel de embajador. Chile está ejerciendo más diplomacia en China. El actual embajador, Octavio Errázuriz, un diplomático de carrera, tiene una importante experiencia en Asia, y su predecesor, el ingeniero Eduardo Arriagada, mantuvo unos vínculos muy estrechos con el lado chino. ${ }^{28}$ Las nuevas oportunidades ofrecidas por la globalización para el comercio y el

${ }^{23}$ De interés en el tema del guoqing es "To Reach China's Consumers adapt to Guo Qing", Harvard Business Review (septiembre-octubre de 1994): 66-74.

${ }^{24}$ Jorge Pierotic y Enrique Subercaseaux, diplomáticos tan comprometidos con el servicio en China y el Lejano Oriente como lo fue Carlos Gallo en los ochenta, son excepciones que confirman la regla.

${ }^{25}$ Entrevista con Luis Soto, gerente en Beijing, 15 de abril de 1990.

${ }^{26}$ Philippe Lasserre y Hellmut Schütte, Strategies for Asia Pacific (Nueva York: New York University Press, 1995 ):196. En los últimos años se ha informado que la creciente importancia de la comunicación llega a niveles obsesivos con el uso del dageda (telëfono celular), "Handy Boom in China. Plappern gehört zum Handwerk", Suddeutsche Zeitung, 22 enero de 1998. ${ }^{27}$ Manfred Wilhelmy y Rosa María Lazo, op. cit., 5, 19.

${ }^{28}$ Véase, por ejemplo, su Carta de Beijing, un boletín mensual publicado por la embajada entre 1994 y 1997 y distribuido en círculos empresariales en Chile. Arriagada también cultivó excelentes relaciones con la prensa china. 
contacto transcultural juegan un papel en la maximización de beneficios. La familiaridad cultural y los datos refinados son formas de contrarrestar la competencia que Chile debe considerar seriamente. Esto implica enviar a docenas de chilenos a Beijing y Taipei. ${ }^{29}$

Pero esto puede ser una tarea difícil. A diferencia de países como Estados Unidos, Australia y Canadá, las nuevas generaciones de estudiantes no crecen en un ambiente multicultural. En las últimas décadas no se ha producido una inmigración de importancia venida de lejos. Esto se traduce en una falta de estímulo para estudiar áreas que no sean Europa o Estados Unidos, hacia donde significativos números de la clase intelectual se dirigen a especializarse. También es importante recordar que el país experimentó una significativa emigración y «fuga de cerebros» después del golpe de Estado de 1973, y, hasta donde se sabe, nadie se refugió en Asia.

Casi todos los funcionarios gubernamentales hoy en funciones que se exiliaron, vivieron en las Américas y en Europa. De regreso al país, han utilizado sus conocimientos y contactos forjados en el exterior en favor de un mejoramiento de las relaciones con los países industrializados de Occidente y con países de América Latina. No hay nada comparable para China. Ese papel lo juegan ex embajadores, activos empresarios y recientes aunque prometedoras instituciones. Aquí destaca la Fundación Chilena del Pacífico. ${ }^{30}$

Por otro lado, nacionales de ascendencia china podrían jugar un importante papel. Los chinos de ultramar han desempeñado un notable papel en la creación de «sociedades» formales e informales a las que tienen acceso la gente del mundo de los negocios del país de acogida y origen. ${ }^{31}$ Nuestro país dispone de un activo en Iquique y Antofagasta, donde se concentra la mayoría de los chilenos de ascendencia china. Por su parte, la inmigración de ese origen se ha incrementado en los últimos años. Han habido varios alcaldes de ascendencia china en el norte del país, incluyendo a un intendente, que, por cierto, ha llegado a ese puesto con la confianza del presidente de la República. ${ }^{32}$

\footnotetext{
${ }^{29}$ Hace medio año, aparte del personal diplomático destinado en Beijing sőlo había seis connacionales en la República Popular China inscritos oficialmente, y ninguno de ellos trabajaba para intereses chilenos. A nivel continental, las cifras también son escuálidas. En 1991, sôlo 120 estudiantes latinoamericanos se especializaban en China. Eduardo Daniel Oviedo, Las relaciones chino-latinoamericanas post-Tiananmen (Buenos Aires: Instituto de Relaciones Internacionales, 1996): 18. Carezco de las cifras de estudiantes chinos en América Latina. Probablemente excedían los doscientos estudiantes en esas fechas, cifra, en todo caso, muy inferior a los entre 20.000 a 25.000 que en 1987 ya se especializaban en Estados Unidos. Véase Orville Schell, Discos and Democracy, (Nueva York: Doubleday, 1986): 296.

${ }^{30}$ La Fundación Chilena del Pacífico fue establecida en novjembre de 1994 por el gobjerno de Chile junto con miembros de la comunidad académica y de negocios para apoyar la integración chilena en la Cuenca del Pacífico. Ya ha comenzado a colaborar con el recientemente creado Centro de Estudios Asiáticos del Instituto de Estudios Internacionales de la Universidad de Chile.

${ }^{31}$ En este punto es de gran utilidad la investigación en curso relacionada con las redes étnicas chinas como factores positivos en las relaciones económicas bilaterales, que pronto publicarán Vitor Trinidade y James Rauch, investigadores de la Universidad de California en San Diego.

${ }^{32}$ Lin Chou, "Relations Between the Republic of China and the Republic of Chile", Occasional Papers/Reprints Series in Contemporary Asian Studies, $n^{\circ}$ (1995): 16.
} 
Pero, pese a la existencia de esta inmigración, su impacto es pequeño en la cultura nacional, así como en la elaboración de las políticas oficiales relacionadas con Beijing y Taipei. ${ }^{33}$

Otra barrera para un mayor involucramiento en China es, obviamente, el factor geográfico. Hay una diferencia de 12 husos horarios entre ambos países y más de 15.000 kilómetros, normalmente cubiertos en vuelos de 24 horas, aunque dentro de poco habrá vuelos directos. A pesar de estas dificultades, la opción por China tiene su base.

La crisis asiática parece conspirar y señalar una luz de advertencia a un creciente involucramiento en la región. Pero, en el largo plazo, un país pequeño como Chile no podrá desatender a ese mercado. Además, las crisis son temporales por definición y Asia dispone de los recursos humanos y económicos para sortearla. Además, la misma coyuntura ha hecho de Beijing un actor más gravitante en Asia, al punto de que se habla que ha desplazado a Tokio como principal factor regional.

Junto a los obstáculos del presente hay signos alentadores. Parece altamente probable la continuación del compromiso chileno en Asia de las dos últimas y consecutivas presidencias. Ricardo Lagos, quien es de acuerdo a las encuestas de opinión un candidato con grandes posibilidades en las elecciones presidenciales de 1999, está convencido de la utilidad de fortalecer los lazos con Beijing. ${ }^{34}$

Hasta hace poco, una mayor participación chilena en Asia -y dentro de ella, el incremento de la importancia del factor chino- ha sido un camino pavimentado y señalado por altos cargos políticos, empresariales y académicos, en consonancia con la estrategia de «puertas abiertas» de libre comercio con múltiples socios, que se adapta a un país pequeño como Chile. ${ }^{35}$

\section{El marco educacional}

Es estimulante pensar que las mismas dificultades que nos alejan culturalmente de Asia esconden un factor positivo. Pese al relativo aislamiento chileno de los principales centros culturales del mundo occidental, el país ha sido tradicionalmente receptivo a la cultura y las ideas provenientes del exterior. Esta apertura hace factible pensar en una inclusión de Asia como una realidad más concreta en la conciencia ciudadana. Ello necesariamente implicaba ajustes en el sistema educacional para corresponder con lo que ha estado ocurriendo en el

\footnotetext{
${ }^{33}$ Este autor no tiene noticia de ningún diplomático chileno de origen chino destinado en Beijing en los últimos doce años. ${ }^{34}$ Véase la entrevista con Ricardo Lagos después de su visita a la República Popular China, El Mercurio, 3 de mayo de 1998. 35 En torno a las alternativas para Chile y los países latinoamericanos en el orden de la postguerra fría, véase Peter Smith, «Introduction: Cooperation or Rivalry? Issues and Themes», en Cooperation or Rivalry? Regional Integration in the Americas and the Pacific Rim (Boulder: Westview Press, 1996): 1-6; Alberto van Klaveren, «América Latina: hacia un regionalismo abjerton, Estudios Internacionales, $\mathrm{n}^{\circ} 117$ (enero-marzo de 1997): 62-78.
} 
comercio exterior del país. Hay que constatar que no se enseña chino en las universidades, en las escuelas de negocios ni se incluye en el curriculum diplomático.

Mirando hacia el futuro, un buen punto de partida es el potencial del currículo escolar. Como se sabe, los textos de Historia son historias oficiales. Su propósito es informar a la siguiente generación de ciudadanos sobre el pasado nacional e integrarles en el mundo contemporáneo. Esto implica un proceso de selección. Los textos mutan, pues son una obra haciéndose que refleja los cambios de la realidad. ${ }^{36}$ Por ejemplo, los libros de texto de Historia y Ciencias Sociales de la década de los ochenta y noventa han incluido acontecimientos políticos y económicos que se han venido desarrollando en los principales países de Oriente.

Aquí se detecta una creciente atención prestada a Asia. En la escuela primaria, Chile es presentado en la red de rutas marítimas del Pacífico, relacionado con el resto de América, Asia y Oceanía. Durante algunas décadas los estudiantes han aprendido que América fue parcialmente poblada por grupos étnicos que trajeron plantas y animales por vía del Estrecho de Behring y por grupos polinésicos provenientes de Oceanía. ${ }^{37}$

Sobre el común ámbito geográfico del Asia-Pacífico se enseña que se trata de una zona de volcanes y terremotos influenciados por el «cinturón de fuego», que abarca a Asia y América. En el terreno comercial el Pacífico es descrito como el «océano del futuro», una cuenca económica común compuesta de importantes países conectados por un vibrante intercambio comercial. Los alumnos aprenden que América del Norte, Japón, México y China, los «dragones del Pacífico» (Taiwan, Corea del Sur, Singapur y Hong Kong) y Chile comparten ese destino.

En el colegio, los chilenos ya se informan que Asia es el continente más extenso, habitado por más de la mitad de la población mundial y cuna de los sistemas más antiguos de escritura, religiones, leyes y rutas comerciales, ciencias y agricultura. Sin embargo, los países del AsiaPacífico se superponen en la percepción con el concepto de Asia como unidad mayor, prolongándose desde la parte oriental del Mar Mediterráneo hasta el Mar de Japón.

Se le sigue concediendo la mayor atención a Japón como superpotencia económica. Pero los manuales de texto también enfatizan la relevancia del país más superpoblado como origen de grandes recursos naturales, organización y mano de obra. En ciertos textos utilizados en la escuela secundaria se da actualísima información sobre las nuevas tendencias en el socialismo chino posmaoísta y ofrecen cifras fundamentales sobre las reformas emprendidas por

\footnotetext{
${ }^{36}$ Vêase un artículo de próxima aparición del profesor Bud Mehan, dentro del marco del «Proyecto de América Latina en la Cuenca del Pacííco", Universidad de California, San Diego, febrero-marzo, 1998.

${ }^{37}$ Ana María Barros et al., Historia y Geografia 2 (Santiago: Arrayan, 1988): 31, 42, 43; Andrea Krebs K., Verónica Matte L., Historia y Geografia 5 (Santiago: Editorial Universitaria, 1997): 17, 75, 167.
} 
Deng Xiaoping y su apertura al mundo exterior bajo el lema del «socialismo de mercado con características chinas". ${ }^{38}$

Por lo menos hasta el año pasado, los cuatro tigres eran también descritos como países que experimentaban un crecimiento ininterrumpido desde 1960 . Un texto reciente subraya los logros económicos de Hong Kong, Singapur, Taiwan y Corea del Sur afirmando que cuatro factores les hacen pertenecer a una región peculiar y de gran potencial: su cercanía con Japón (tecnología y capitales); su fácil acceso a las zonas marítimas con antigua tradición comercial; y su numerosa población urbana en una cultura que premia la habilidad y la ética laboral. También se subraya la docilidad de la fuerza laboral (bajas demandas salariales), y las facilidades dadas a las multinacionales en estos socios comerciales de Chile. ${ }^{39}$ En los textos hay información relevante para los empresarios y políticos del mañana.

Pero hay un detalle importante. Los contenidos de los manuales no necesariamente dictan el contenido de las clases. Y sobre todo, el éxito de cualquier ajuste curricular depende de los conocimientos de los docentes. Hasta hoy, aparte de nuestra historia nacional nos concentramos en América Latina y Europa. La cultura occidental sigue siendo altamente valorada y un factor de prestigio.

Entre las formas de mejorar nuestra percepción de Oriente podríamos considerar el envío de profesores de enseñanza primaria y secundaria a China en el marco de los convenios educacionales bilaterales e incluirles más a menudo en las delegaciones oficiales.

\section{Recomendaciones}

No está fuera de lugar plantear una serie de sugerencias para profundizar las relaciones con el continente chino, potencial superpotencia económica y científica. A los valiosísimos pasos dados por Chile en los últimos años se podrían agregar medidas adicionales de largo alcance, a saber:

1.- Modificar partes del currículo escolar. Como consecuencia de la globalización más pronto que tarde el sistema educativo deberá afrontar el reforzamiento en la enseñanza del inglés e incluir al chino como alternativa. ${ }^{40}$ Las escuelas privadas podrían considerar eliminar

${ }^{38}$ P. Benejam et al., Horizonte 2. Historia y Geografia. Segundo Año de Educaciōn Media (Santiago: Editorial Andrés Bello, 1995): 238-239. Para una amplia cobertura sobre los acontecimientos contemporáneos -texto distribuido en Chile y España, vêase Miguel Artola y Manuel Pérez, Historla del Mundo Contemporáneo (Barcelona: Anaya, 1993 ).

39 P. Benejam, op. cit: 239. Para una presentación de Asia en la escuela primaria y secundaria, vêase Reneé Viñas Joan, ed., Historia y Geografía 8 (Santiago: Santillana, 1982); Lenka Domic, Sergio Villalobos, Ricardo Krebs, Historia y Geografia. $5^{\circ}$ Año Básico (Santiago: Editorial Universitaria, 1980). Para un relato actualizado de la accesión de Chile en APEC utilizado en el curriculo escolar, vẻase Alejandro Concha et al., Historia de Chile (Santiago: Bibliográfica Internacjonal, 1995 ): $764-766$.

${ }_{40}^{\circ}$ El chino escrito es una base útil para el estudiante que posteriormente desee estudiar japonés. 
el francés o el alemán como segunda lengua, teniendo en cuenta que en Oriente el chino está incrementando su presencia como idioma regional.

2.- Crear un espacio para Asia en los medios de comunicación de masas. La difusión de lenguas y culturas ayuda a estrechar la brecha de entendimiento. Aquí el gobierno y el sector privado son las naturales fuentes de financiamiento. En la próxima década los países asiáticos pueden encontrar interesante apoyar la idea. El ejemplo alemán es un modelo útil. Durante décadas, Alemania se ha promocionado en los cines chilenos, antes del filme principal, por medio de la proyección del noticiario UFA, referido a cultura, ciencia y deportes.

3.- Reforzar la cobertura de noticias generales y especializadas. Se necesita información para analizar la actuación económica y las perspectivas, la evolución de la reforma y la liberalización, las características del proceso de descentralización, los compromisos respecto a la negociación de ingreso en la Organización Mundial de Comercio, entes de investigación y actores económicos y financieros. Para identificar oportunidades para los países latinoamericanos sería aconsejable crear un consorcio de especialistas de la región que sirva a las embajadas de los países del Pacífico americano y el MERCOSUR.

4.- En vista de la diversidad y las probables oportunidades ofrecidas por diferentes provincias, preparar a una nueva generación de estudiantes universitarios, hombres y mujeres de negocios y diplomáticos especializados en China y en varias de sus regiones. Actualmente se cubren cuatro principales ciudades estratégicas. Además de la embajada en Beijing, se cuenta con el flamante consulado en Shanghai, y cuatro oficinas comerciales de ProChile en Hong Kong, Cantón Beijing y Taipei. Opciones adicionales son aperturas de oficinas en Tianjin, un puerto significativo en la China septentrional, y en Tongling -provincia de Anhui-, ciudad hermana de Antofagasta, ambos centros distribuidores de sus respectivos países.

5.- Debido a su pequeño tamaño, Chile debiera apoyar la idea de establecer un centro de informaciones latinoamericano o de MERCOSUR en Shanghai, que, de acuerdo a las proyecciones de hoy en día, será la ciudad más significativa de Asia dentro de 20 años. Un ente así está llamado a convertirse en un punto de formación y encuentro. Podría tratarse de una institución que ofreciese cursos a nivel de Magister para ejecutivos de alto nivel de compañías estatales, empresas conjuntas o de la administración pública. Los seminarios pueden incluir encuentros regulares con funcionarios gubernamentales y ejecutivos de compañías locales y multinacionales. Aquí los fondos gubernamentales, del sector privado y del Banco Interamericano de Desarrollo son las naturales fuentes de financiamiento.

6.- Analizar el potencial representado por los chinos residentes y los chilenos de ascendencia china en Chile e incluir a miembros destacados de estos grupos en instituciones relevantes vinculadas a las relaciones bilaterales. Los procesos de decisión con respecto a la «Gran China», las delegaciones comerciales y culturales a Beijing y Taipei se beneficiarían 
con la presencia de este hasta ahora discreto colectivo. Igualmente, sería provechoso explorar formas de contactar permanentemente con personalidades de provincias como Fujian y Guangdong inmersas en influyentes redes comerciales.

Pese a los efectos de la crisis asiática, un mayor compromiso en varios frentes y de largo plazo, en China y Oriente, puede maximizar el resultado de nuestros actuales esfuerzos. 